\title{
A response to "Highlighting the value of impact evaluation: enhancing informal science learning and public engagement theory and practice"
}

\section{Heather King and Kate Steiner}

Abstract

Keywords
Whilst welcoming Jensen's response to our original paper, we suggest that our main argument may have been missed. We agree that there are many methods for conducting impact assessments in informal settings. However, the capacity to use such tools is beyond the scope of many practitioners with limited budgets, time, and appropriate expertise to interpret findings. More particularly, we reiterate the importance of challenging the prevailing policy discourse in which longitudinal impact studies are regarded as the 'gold standard', and instead call for a new discourse that acknowledges what is feasible and useful in informal sector evaluation practice.

Science centres and museums; Public engagement with science and technology; Informal learning

We welcome this response by Jensen [2015] to our article 'Highlighting the value of evidence-based evaluation: pushing back on demands for impact' [King et al., 2015]. Clearly, Jensen shares our view that evaluation studies for informal science learning institutions and public engagement initiatives can provide essential practical insights. Indeed, this is the central thrust of our original paper.

In our paper, we offered an illustrative example of how evaluation informed ongoing and future practice of a museum-based teacher professional development programme. We noted both the affordances and the deficiencies of our evaluation, discussing the limitations in detail. In response to Jensen's comments, we acknowledge that there are other methodological approaches that we could have adopted. We are disappointed, however, that Jenson has focused on critiquing our illustrative example and, as such, appears to have missed our main argument regarding the limited capacity for many informal science learning practitioners to engage in specialist social science research of the sort required for longitudinal impact assessment.

There are, of course, various instruments suitable for conducting evaluation in informal settings, some of which are available though open-source technology [see Jensen, 2015]. However, we would argue strongly that the efficacy of such tools depends on the expertise and resources of those using them. Whilst some informal sector practitioners may have the professional training and also the necessary time 
and budget allotted within their everyday roles to conduct, for instance, intervention studies, such tasks are beyond the scope of the majority.

Jensen [2015] suggests that informal learning and engagement practice has 'long eschewed a robust evidence-based approach to long-term improvement' and that institutions are thus in part to blame for the recent and growing demands for impact by funders. He argues that the present emphasis on impact is an opportunity to negotiate a more scientific approach to informal sector practices. We agree that there is a need to bring this issue into the arena for wider debate. We would also join him in his calls for additional staff training, increased allocation of resources and the use of more sophisticated techniques to examine practice. However, we argue that it is equally important to challenge the prevailing policy discourse in which longitudinal impact studies, with randomized control populations, are regarded as the 'gold standard' and, as such, are supported and promoted by large-scale funding. In the U.K., for example, the Engagement Endowment Fund has received $£ 125$ million from the Department of Education to conduct longitudinal assessments of educational programmes according to a set of prescribed minimum standards using randomized controlled trials (see https://educationendowmentfund.org.uk). Such levels of funding and political support will inevitably shape expectations of what is required, and even regarded as standard, with respect to evaluation. As discussed in our paper, few informal science learning institutions have the in-house skills or finances to conduct such studies.

We welcome future discussions in this journal relating to the design, implementation and consequences of evaluation approaches. In the meantime, we continue to urge for a pushing back on demands for longitudinal impact and instead call for a new discourse that acknowledges what is both feasible and useful with regards to informal sector evaluation practice.

References

Jensen, E. (2014). 'The problems with science communication evaluation'. JCOM 13 (01), C04. URL: http://jcom.sissa.it/archive/13/01/JCOM_1301_2014_C04.

- (2015). 'Highlighting the value of impact evaluation: enhancing informal science learning and public engagement theory and practice'. JCOM 14 (03), Y05. URL: http://jcom.sissa.it/archive/14/03/JCOM_1402_2015_Y05.

King, H., Steiner, K., Hobson, M., Robinson, A. and Clipson, H. (2015). 'Highlighting the value of evidence-based evaluation: pushing back on demands for 'impact'. JCOM 14 (02), A02. URL: http://jcom.sissa.it/archive/14/02/JCOM_1402_2015_A02.

\section{Authors}

Heather King is a Research Fellow at King's College London. Her research focuses on the role and function of informal science learning institutions and, in particular, the pedagogical practices of informal educators. She also has extensive experience of designing and conducting evaluation studies for a number of EU funded initiatives. E-mail: heather.1.king@kcl.ac.uk. 
Kate Steiner is currently Editor of the new Science Museum Group Journal, an open-access online journal publishing scholarly articles relating to the work and interests of the Science Museum Group. Kate was previously head of Audience Research at the Science Museum Group and has led many research and policy initiatives in the field of visitor studies. E-mail: Kate.Steiner@sciencemuseum.ac.uk.

How to cite

King, H. and Steiner, K. (2015). 'A response to "Highlighting the value of impact evaluation: enhancing informal science learning and public engagement theory and practice"'. JCOM 14 (03), L01. 